\title{
EL MERCADO COMO CONDICIÓN PARA UNA TEORÍA INSTITUCIONAL DE LA JUSTICIA EN AXEL HONNETH
}

\author{
Cecilia Gallardo-Macip \\ Universidad de los Andes, Santiago, Chile \\ Contacto: cgallardo@miuandes.cl
}

Recibido: 5 de octubre de 2020

Aprobado: 12 de diciembre de 2020

Para citar este artículo:

Gallardo-Macip, C. (2021). "El mercado como condición para una teoría institucional de la justicia en Axel Honneth".

Prudentia Iuris, N. 91, pp. 127-156

DOI: https://doi.org/10.46553/prudentia.91.2021.pp.127-156

\begin{abstract}
Resumen: Al encontrarse con una sociedad sumamente individualista, el actual epígono de la Escuela de Frankfurt, Axel Honneth, presenta un estudio sobre la construcción de una nueva teoría institucional de la justicia. Debido a la falta de instituciones capaces de propiciar el reconocimiento de la dignidad y la libertad de todos los miembros dentro de una sociedad, el filósofo alemán argumenta que las relaciones personales, el mercado y la vida política son las tres instituciones necesarias para la elaboración de una teoría de la justicia. En ese sentido, este escrito argumenta, principalmente, de qué manera el mercado es capaz de propiciar un tipo de libertad que no conciba a los sujetos como átomos aislados y egoístas. Además, si bien es cierto que la propuesta de Honneth es blanco de agudas críticas, el diagnóstico y el análisis que realiza aportan una visión totalmente nueva al modo en que concebimos las sociedades capitalistas contemporáneas.
\end{abstract}

Palabras clave: Mercado, Justicia, Reconocimiento, Axel Honneth, Esferas sociales. 


\title{
The Market as a Condition for an Institutional Theory of Justice in Axel Honneth
}

\begin{abstract}
When encountering a highly individualistic society, the current epigone of the Frankfurt School, Axel Honneth, provides a study on the construction of a new institutional theory of justice. Due to the lack of institutions capable of promoting the recognition of the dignity and freedom of all the members within a society, the german philosopher argues that personal relationships, the market, and political life are the three necessary conditions for the elaboration of a theory of justice. In this sense, this writing argues, mainly, in what way the market can foster a type of freedom that does not conceive subjects as isolated and selfish atoms. And although it is true that Honneth's proposal is the target of sharp criticism, the diagnosis and analysis that he carries out contributes to a totally new vision of the way in which we conceive contemporary capitalist societies.
\end{abstract}

Keywords: Market, Justice, Recognition, Axel Honneth, Social spheres.

\section{Il mercato come condizione per una teoria istituzionale della giustizia in Axel Honneth}

Sommario: Trovandosi con una società altamente individualista, l'attuale epigone della Scuola di Francoforte, Axel Honneth, presenta uno studio sulla costruzione di una nuova teoría istituzionale della giustizia. A causa della mancanza di istituzioni in grado di promovuere il riconoscimento della dignità e della libertà di tutti i membri all'interno di una società, il filosofo tedesco sostiene che i rapporti personai, il mercato e la vita política sono le tre istituzioni necessarie per l'elaborazione di una teoría della giustizia. In questo censo, questo scritto sostiene, principalmente, in che modo il mercato é in grado di promuovere un tipo di libertá che non concepisca i soggetti come atomi isolati ed egoisti. Inoltre, mentre è vero che la proposta di Honneth é oggetto di aspre critiche, la diagnosi e l'analisi che egli conduce forniscono una visione totalmente nuova del modo in cui concepiamo le società capitaliste contemporanee. 
Parole chiave: Mercato, Giustizia, Riconoscimento, Axel Honneth, Sfere sociali.

\section{Introducción*}

Mucho se ha escrito sobre el reconocimiento en Axel Honneth ${ }^{1}$, sin embargo, el tema del mercado y su crítica al individualismo capitalista no ha recibido todavía la suficiente atención. Es mi interés ahondar en este tema en específico y contribuir a la discusión, ampliando la escasa bibliografía en español que hay al respecto.

En su libro, El derecho de la libertad, Axel Honneth sugiere, de un modo polémico, que el mercado es una esfera social de la justicia. La tesis del actual epígono de la Escuela de Frankfurt postula que, aun dentro de una sociedad capitalista e individualista, el mercado -así como las relaciones personales y la vida pública- puede ser una institución capaz de propiciar el reconocimiento y la libertad de los individuos. Es decir, Honneth afirma que, para hablar de una sociedad justa en la actualidad, es necesario que las distintas instituciones de un orden social sean capaces de asegurar el desenvolvimiento pleno de los individuos ${ }^{2}$. Ahora bien, Honneth concibe esas instituciones como tres esferas interrelacionadas que, por definición, constituyen prácticas de mutuo reconocimiento ${ }^{3}$. Estas son: a) las relaciones

* Agradezco el apoyo de la Beca Josefina Cruzat de Larraín para la publicación de este artículo.

1 Algunos de los estudios realizados acerca del reconocimiento en Honneth son: Karin de Boer, "Beyond Recognition? Critical Reflections on Honneth's Reading of Hegel's Philosophy of Right"; Stéphane Haber, "Recognition, justice and social pathologies in Axel Honneth's recent writings"; Gazi Islam, "Recognition, Reification, and Practices of Forgetting: Ethical Implications of Human Resource Management"; Gonçalo Marcelo, "Recognition and Critical Theory Today: An Interview with Axel Honneth"; Lois McNay, "The Trouble with Recognition: Subjectivity, Suffering, and Agency"; Neil Roberts, "Recognition, Power, and Agency: The Recent Contributions of Axel Honneth to Critical Theory"; Volker Schmitz, Axel Honneth and the Critical Theory of Recognition; Bart van Leeuwen, "A Formal Recognition of Social Attachments: Expanding Axel Honneth's Theory of Recognition”; Luis Alfonso Zúñiga y Harold Valencia López, "La teoría del reconocimiento de Axel Honneth como teoría crítica de la sociedad capitalista contemporánea"; Christopher F. Zurn, "Recognition, Redistribution, and Democracy: Dilemmas of Honneth's Critical Social Theory". Después, para ahondar en temas de reconocimiento véanse los siguientes textos de Axel Honneth: La lucha por el reconocimiento, The I in We, Reificación: Un estudio en la teoría del reconocimiento; El derecho de la libertad; ¿Redistribución o reconocimiento?; "Recognition and Moral Obligation"; "Recognition and Justice: Outline of a Plural Theory of Justice"; "From Struggles for Recognition to a Plural Concept of Justice: An Interview with Axel Honneth".

2 Honneth, A. (2014). El derecho de la libertad. Buenos Aires. Katz, 173.

3 La teoría del reconocimiento en Honneth es fundamental para el desarrollo de su 
personales, b) el mercado y c) la vida política. Propone estas tres esferas porque cree que son capaces de mitigar el intenso individualismo que caracteriza a las sociedades contemporáneas ${ }^{4}$. Además, las elige porque considera que pueden desarrollar diversos tipos de reconocimiento. Por tanto, afirma que realizar una reconstrucción normativa ${ }^{5}$ de estas tres esferas prácticas

sistema antropológico y político. En su obra culmen, La lucha por el reconocimiento, Honneth, retomando a Hegel, describe: "El movimiento de reconocimiento, que subyace en la relación ética entre los sujetos, consiste en un proceso de etapas de reconciliación y de conflictos, separados unos de otros". Honneth, A. (1997). La lucha por el reconocimiento. Por una gramática moral de los conflictos sociales. Barcelona. Grijalbo, 28. En otras palabras, también podría decirse que "el reconocimiento mutuo consiste en una experiencia recíproca en la que uno mismo es consciente de los objetivos del otro, ya que la existencia del otro representa una condición de posibilidad para llevar a cabo objetivos y deseos propios". Cfr. Coronado-Angulo, C. (2019). Razón instrumental, sociedad e instituciones. Una semblanza de Max Weber y la Escuela de Frankfurt. Pamplona. EUNSA, 237. Ahora bien, este principio resulta imprescindible para explicar la justificación de su teoría de la justicia y el por qué, según Honneth, la teoría de distribución defendida por John Rawls no es suficiente para hablar de una sociedad justa. Cfr. Honneth, A. y Markle, G. (2004). "From Struggles for Recognition to a Plural Concept of Justice: An Interview with Axel Honneth". Acta Sociológica, 47(4), 383. Desde su obra Reificación: un estudio en la teoría del reconocimiento, Honneth observa que las sociedades contemporáneas se caracterizan por una constante cosificación del ser humano. Retomando el término de Lukács, afirma que esta deformación en las relaciones humanas implica una perspectiva equivocada del mundo. El problema es que esta visión del mundo señala patologías sociales, ya que se olvida el valor del ser humano y termina por ser instrumentalizado y cosificado. Cfr. Honneth, A. (2007). Reificación: un estudio en la teoría del reconocimiento. Buenos Aires. Katz, 10-17.

4 Cfr. "Mi Introducción" intenta presentar, siguiendo a Hegel aquí también, que en las sociedades democráticas liberales modernas estos valores están fusionados en uno solo, a saber, la libertad individual en la multiplicidad de los significados conocidos por nosotros. Por lo tanto, cada esfera constitutiva de nuestra sociedad encarna -esto afirma la premisa de partida de mi estudio- un determinado aspecto de nuestra experiencia de libertad individual". Honneth, A. El derecho de la libertad. Ob. cit., 10.

5 La reconstrucción normativa, para Axel Honneth, es la metodología de investigación que utiliza para realizar su diagnóstico de las sociedades contemporáneas. Pero sobre todo, es el punto de partida para la elaboración de su teoría de la justicia. En las palabras de Honneth: "Reconstrucción' querrá decir que del conjunto de rutinas y organismos sociales solo se tomarán y presentarán aquellos que puedan considerarse imprescindibles para la reproducción social, y puesto que los objetivos de la reproducción se deben establecer en esencia mediante los valores aceptados, la reconstrucción 'normativa', entonces, implica necesariamente ordenar en la presentación las rutinas y las entidades según el grado en que aportan, dentro de la división del trabajo, a la estabilización y la puesta en práctica de esos valores". Honneth, A. El derecho de la libertad. Ob. cit., 15. Tal análisis fáctico e histórico, que consiste en la reconstrucción normativa, es crucial para la elaboración de la teoría de la justicia, puesto que, "en el intento de desarrollar una concepción de la justicia por la vía teórico-social debe suponerse en una primera premisa que la forma de reproducción social de una sociedad dada está determinada por valores e ideales generales y compartidos; tanto los objetivos de la producción social como los de la integración cultural son regulados en última instancia mediante normas que poseen un carácter ético en cuanto contienen representacio- 
podría fortalecerlas para que estas puedan disminuir, a su vez, la atomización de los individuos en un contexto liberal ${ }^{6}$. Sin embargo, para exponer la teoría institucional sobre la justicia de Honneth, es preciso comprender, principalmente, dos factores.

En primer lugar, Honneth comienza su argumentación a partir de una crítica a las nociones de libertad negativa y libertad positiva desarrolladas por Isaiah Berlin ${ }^{7}$, para explicar que, si se quiere hablar de una sociedad justa, es necesario que las instituciones aseguren un tipo de "libertad social" en favor de bienes que no sean meramente individuales, sino compartidos. Honneth bautizará esta libertad como "social" porque apunta al hecho de que los individuos no pueden considerarse enteramente libres si no tienen presente que, para serlo, deben estar insertos en un conjunto social ${ }^{8}$.

En segundo lugar, elabora su teoría a partir de un análisis fáctico e histórico de la sociedad ${ }^{9}$. Desde ahí, Honneth reconstruye las tres esferas

nes del bien compartido conjuntamente. En la segunda premisa se sostiene, como una primera aproximación, que el concepto de justicia no puede ser entendido independientemente de estos valores que abarcan todo el ámbito de lo social: debe valer como 'justo' aquello que en las prácticas o instituciones dentro de una sociedad tiende a realizar los valores que en cada caso son aceptados como generales. Solo con la tercera premisa se manifiesta lo que significa más precisamente desarrollar una teoría de la justicia sobre la base de las dos determinaciones precedentes; esto quiere decir destilar o, hablando metódicamente, reconstruir normativamente a partir de la multiplicidad de la realidad social aquellas instituciones o prácticas que realmente pueden contarse como apropiadas para asegurar y realizar los valores generales. Con la cuarta premisa se debe garantizar que la aplicación de tal procedimiento metódico no lleve a que solo se afirmen las instancias ya existentes de la eticidad; si se la ejecuta estrictamente, se deberá desarrollar la reconstrucción normativa hasta el punto en el que, dado el caso, pueda verse claramente en qué medida las instituciones y prácticas éticas no representan con la suficiente amplitud o completitud los valores generales que encarnan”. Honneth, A. El derecho de la libertad. Ob. cit., 24-25.

6 McNay, L. (2015). "Social Freedom and Progress in the Family: Reflections on Care, Gender and Inequality”. Critical Horizons, 16(2), 173.

7 Cfr. Berlin, I. (1969). "Two concepts of liberty". En On Liberty. New York. Oxford University Press.

8 Cfr. Coronado-Angulo, Razón instrumental, sociedad e instituciones. Una semblanza de Max Weber y la Escuela de Frankfurt. Ob. cit., 251.

9 Como ex director del Instituto de Investigación Social, Axel Honneth podría considerarse como miembro de la tercera generación de la Escuela de Frankfurt y precursor de la Teoría Crítica, puesto que se hace cargo de ciertas preocupaciones e intereses que los fundadores de la Escuela (Max Horkheimer, T. W. Adorno y Herbert Marcuse) poseían; a saber, la justicia, la instrumentalización y cosificación de los seres humanos, el análisis de patologías sociales, el estudio interdisciplinario y la crítica a sociedades capitalistas; véase: Jeffries, S. (2017). Grand Hotel Abyss: The Lives of the Frankfurt School. Scotland. Verso; Coronado, Razón instrumental, sociedad e instituciones. Una semblanza de Max Weber y la Escuela de Frankfurt. Ob. cit.; Wiggershaus, R. (2011). La Escuela de Fráncfort. México. FCE; Horkhe- 
que propiciarían, desde su perspectiva, el desarrollo de la libertad social: para el autor, un sujeto es libre si asume que debe actuar dentro de un marco de prácticas institucionalizadas, en donde tiene que considerar a otros para alcanzar sus propios objetivos ${ }^{10}$. Tales instituciones se caracterizan por encarnar comportamientos sociales que invitan a las personas a actuar de manera complementaria a través de ciertas reglas y normas. Por tanto, las instituciones de reconocimiento son la base para el desenvolvimiento de los individuos ${ }^{11}$. Ahora bien, la elección de las tres esferas se debe a que

imer, M. Teoría Crítica; Honneth, Reificación: un estudio en la teoría del reconocimiento, La lucha por el reconocimiento. Ob. cit.; Roberts, N. (2009). "Recognition, Power, and Agency: The Recent Contributions of Axel Honneth to Critical Theory". Ahora bien, por otro lado, también es cierto que Honneth se aleja de los intereses iniciales de Horkheimer y Adorno. Incluso, en la obra de Honneth, titulada Crítica del poder: Fases en la reflexión de una Teoría Crítica de la sociedad, enuncia las deficiencias de la Teoría Crítica. En primer lugar, Max Horkheimer y Theodor Adorno fallan en darle una visión mucho más sociológica a la Teoría Crítica, quedándose únicamente en una suerte de filosofía de la historia que reduce los procesos sociales a una lectura de dominación de la naturaleza. Cfr. Honneth, A. (1995). "Social Deficit of Critical Theory". En New Perspectives on Max Horkheimer. MIT Press, 187-214; (2009). Crítica del poder: Fases en la reflexión de una Teoría Crítica de la sociedad (Teoría y crítica $\mathrm{n}^{\circ}$ 23) (Spanish Edition). Antonio Machado Libros. Edición de Kindle. En segundo lugar, si bien le concede a Habermas la importancia de revitalizar el espacio público, Honneth afirma que hace falta un fortalecimiento de las tres esferas sociales que considera tan importantes: familia, mercado y vida pública-democrática. Además, Honneth se enfoca en una lectura más sociológica y antropológica de la sociedad. Cfr. Honneth, Crítica del poder. Ob. cit.; Coronado, Razón instrumental, sociedad e instituciones. Ob. cit.; Roberts, "Recognition, Power, and Agency: The Recent Contributions of Axel Honneth to Critical Theory”. Ob. cit.; Zúñiga, L. A. y López, H. V. (s. f.). "La teoría del reconocimiento de Axel Honneth como teoría crítica de la sociedad capitalista contemporánea". Reflexión política.

10 Cf. Honneth. El derecho de la libertad. Ob. cit., 85.

11 Cf. Honneth. El derecho de la libertad. Ob. cit., 86. Como se ha afirmado, en la tradición de la Escuela de Frankfurt -en la que Honneth se ha desarrollado- no se definen los conceptos que utilizan, sino que son descritos y contextualizados. Cfr. Jeffries, Grand Hotel Abyss. Ob. cit.; Wiggershaus, La Escuela de Fráncfort. Ob. cit.; Jay, M. (1989). La imaginación dialéctica: Historia de la Escuela de Frankfurt y el Instituto de Investigación Social 1923-1950. Madrid. Taurus. Esto, a su vez, implica grandes deficiencias y dificultades para comprender la argumentación de Honneth. En el caso del reconocimiento es lo mismo: "La razón de este objetivo se deriva de la tesis que Honneth toma de Georg W. F. Hegel y de Herbert G. Mead, de que los sujetos pueden relacionarse consigo mismos en orden a la realización de acciones sólo si pueden verse a sí mismos reflejados en las normas que sustentan y respetan sus compañeros sociales. Por lo tanto, este principio fuerza a los individuos a dar contenido a sus pretensiones de reconocimiento recíproco, para poder desarrollar su subjetividad. Honneth sostiene que estas relaciones de reconocimiento en las que el sujeto debe entrar para poder relacionarse consigo como un agente capaz pueden agruparse en tres categorías: el amor, el derecho y la solidaridad. Estas formas de reconocimiento permiten al sujeto establecer relaciones consigo mismo que le permitan actuar libremente, que consisten en la autoconfianza, el autorrespeto y la autoestima”. Arrese Igor, H. (2017). "El mercado como una esfera de libertad social". Filosofía de la Economía 6 (2), 140. 
Honneth las define como las realidades sociales que representan el tipo de reconocimiento que se presenta en una democracia liberal contemporánea. En ese sentido, Honneth menciona: “[...] el contexto institucional es un componente nuclear de la libertad, pues, sin ellas, los individuos no podrían saber de su dependencia mutua"12. En otras palabras, la importancia de las instituciones radica en que estas son fundamentales para la construcción de una teoría de la justicia ya que Honneth desea mostrar que solamente es posible hablar de una sociedad justa si las relaciones entre individuos son concebidas como necesarias.

En esa línea, y una vez establecido el marco teórico de la propuesta de Honneth, en el presente trabajo se pretende argumentar en qué medida sería posible afirmar que el mercado, una esfera social en la cual los individuos tienden a buscar bienes privados, es necesario para formular una nueva teoría de la justicia ${ }^{13}$. Sobre todo, porque, para Honneth, la esfera del mercado puede cumplir su función solamente si se integran armoniosamente las actividades económicas de los individuos, junto con el resto de las instituciones ${ }^{14}$. Considera, incluso, que el mercado es fundamental para la elaboración de una teoría de la justicia, ya que conlleva un tipo de reconocimiento que permite a las personas participar en actividades complementarias y, además, es capaz de conciliar la esfera familiar con la política. También es necesario aclarar que su teoría de la justicia constituye un conjunto de principios y normativas, al igual que un perpetuo proceso inacabado donde se realiza un constante análisis del contexto social. Es decir, su teoría busca ver de qué manera las instituciones, en un tiempo y espacio determinado, encarnan valores que sirven para asegurar la libertad y el desarrollo de los individuos.

Ahora bien, para mostrar cómo es posible defender la tesis de $\mathrm{El} d e$ recho a la libertad, se expondrán las críticas a las nociones de libertad articuladas por Isaiah Berlin, para explicar en qué consiste la libertad social propuesta por Honneth. A continuación, se examinará la relación entre las tres esferas institucionales (vínculos personales, mercado y vida política) y el tipo de reconocimiento que propicia cada una para argumentar por qué son necesarias para el desarrollo de la libertad social. En este punto, se profundizará en los atributos fundamentales del mercado y, se analizará, especialmente, cómo Honneth defiende que esa institución es capaz de fomentar la libertad social. También se reconstruirá la teoría institucional de

12 Coronado, C. (2018). "La libertad como condición de la justicia según Axel Honneth". Revista de filosofía open insight, 9 (15), 156.

13 Cf. Honneth. El derecho de la libertad. Ob. cit., 232.

14 Cf. Jütten, T. (2015). "Is the Market a Sphere of Social Freedom?" Critical Horizons, $16(2), 181$. 
la justicia y se justificará por qué el mercado es necesario para elaborarla. Consecuentemente, se expondrán las dos principales críticas que ciertos autores dirigen a la propuesta de Honneth, a saber: (i) que es iluso pensar que el mercado posee características morales por los cuales sus actores no buscarán los mayores beneficios personales, sino lo mejor para los demás individuos; y que (ii) la reconstrucción normativa del mercado en realidad busca imponerle propiedades que por naturaleza no posee, provocando que toda la teoría de la justicia de Honneth sea inviable. Por último, se examinará si las críticas al modelo de Honneth son consecuentes y de qué manera dicho modelo puede aportar una nueva manera de comprender el mercado como una institución capaz de fomentar la libertad social y, a su vez, conformar una teoría institucional de la justicia.

\section{Tres nociones de libertad ${ }^{15}$}

El estudio de Honneth surge tras realizar un preocupante diagnóstico sobre las democracias liberales en la actualidad. En su investigación, descubrió un valor que, según el filósofo alemán, ha impactado a las sociedades contemporáneas y provocado una malinterpretación de la justicia, y, por ende, de la libertad. En palabras de Honneth: "Entre todos los valores éticos que llegaron a imperar en la sociedad moderna y que desde entonces compiten por una posición dominante, solo uno era apto para marcar de manera duradera nuestra idea de la justicia: la libertad entendida como la autonomía del individuo"16. Por tanto, es necesario examinar en qué medida el orden social se ha encargado de fomentar la autonomía individual. Sobre todo, porque para Honneth: "Todos los ideales éticos de la Modernidad han entrado, como por mágica atracción, en la órbita de una idea de la libertad; por momentos la profundizan, le otorgan nuevos matices, pero no le oponen

15 Para la elaboración de una teoría de la justicia en Honneth, es necesario reparar en que los conceptos de libertad y de justicia están íntimamente conectados. "Si bien las conexiones metódicas entre la idea de la libertad y la idea de la justicia se presentan como inequívocas en el campo de la autodeterminación, se vuelven ambiguas no bien la libertad reflexiva del individuo es interpretada según el modelo de la 'autorrealización' o de la 'autenticidad'. Lo que se entiende en cada caso por justicia en la Modernidad depende -así lo hemos visto- casi exclusivamente de cuál sea la idea de libertad individual presupuesta; si la libertad es pensada como un acto reflexivo y esta reflexión es interpretada como un largo proceso de toda la vida de articulación del propio yo, entonces la concepción resultante de justicia debe poder hacer concebible un sistema en el cual cada sujeto está en condiciones de autorrealizarse sin perjudicar a los demás". Honneth. El derecho de la libertad. Ob. cit., 58-59. En ese sentido, hablar de justicia social implica aceptar el ejercicio individual de la libertad.

16 Honneth. El derecho de la libertad. Ob. cit., 29. 
ya una alternativa autónoma"17. Es decir, las nociones modernas de libertad establecieron determinadas maneras de comprender a un sujeto libre, sin tomar en cuenta que es posible formular otra definición capaz de conciliar armoniosamente los intereses de los individuos.

Ahora bien, el análisis de la libertad debe comenzar, según Honneth, a partir de la observación del discurso moral de la Modernidad. En ese período histórico, surgen tres modelos que conciben de manera diferente la estructura y el carácter de las intenciones individuales. Hay que evidenciar cuáles son las principales características de cada tipo de libertad para así lograr entender por qué su definición debe incluir una noción de reconocimiento. Más aún, de acuerdo con sus niveles de creciente complejidad, Honneth clasifica la libertad en tres tipos: (i) negativa ${ }^{18}$, (ii) reflexiva o positiva ${ }^{19}$ y (iii) social. En cuanto a las dos primeras, se remite a la distinción realizada por Isaiah Berlin $^{20}$. La tercera retoma la teoría institucional de Hegel en su Filosofía del Derecho ${ }^{21}$.

Honneth identifica a Thomas Hobbes como el primero en formular la libertad negativa; no obstante, Berlin le agrega a esa definición la idea de que los individuos reciben el derecho de actuar arbitrariamente sin una restricción externa siempre y cuando no infrinjan los mismos derechos que

17 Ibídem, 30.

18 La libertad negativa puede encontrar su origen en Thomas Hobbes donde, en un pasaje de El Leviatán, señala que la libertad consiste en la mera ausencia de obstáculos externos que obstruyan el movimiento natural de un cuerpo. En ese sentido, Honneth retoma únicamente la definición hobbesiana de libertad natural: "En el nivel más elemental, la 'libertad', para Hobbes, no es otra cosa que la ausencia de resistencias externas que podrían impedir el movimiento a los cuerpos naturales". Honneth. El derecho de la libertad. Ob. cit., 36. Sobre todo, es importante destacar que, para Honneth, la propuesta hobbesiana de entender la libertad solamente como la realización sin impedimentos externos de objetivos propios opacó a las ideas de libertad que podían impulsar el deseo de constituir asociaciones civiles; sin embargo, fue la formulación "extremadamente estrecha y negativa que pasó a la historia". Ahora bien, es precisamente por esta lectura de Hobbes, que Honneth afirma que la idea de libertad, con la que operan las teorías de la justicia, resulta en una noción del hombre como un ser atómico que no posee otro interés que el de actuar "sin restricciones, según sus propias preferencias circunstanciales". Honneth. El derecho de la libertad. Ob. cit., 42. Véase como antecedente también: Honneth, A. (2012). The I in We. Cambridge. Polity Press, 37-38.

19 En cuanto a la libertad positiva o reflexiva, Honneth afirma que puede rastrearse hasta la Antigüedad y que esta consiste en la capacidad de autodeterminarse; es decir, los individuos son libres cuando sus acciones son guiadas solamente por sus propias intenciones. Cfr. Honneth. El derecho de la libertad. Ob. cit., 29.

20 Cfr. Honneth. El derecho de la libertad. Ob. cit., 19. Con respecto al modo en que Honneth retoma la visión de Berlin, véase: Okochi, T. (2012). "Freedom and Institution: Theory of Justice as Hegelian 'Sttlichkeitslehre' in a Honneth's 'Das Recht der Freiheit”. Hitotsubashi Journal of Social Studies, 44 (1).

21 Cf. Honneth. El derecho de la libertad. Ob. cit., 15. 
poseen sus conciudadanos ${ }^{22}$. Con respecto a esto, Honneth piensa que esta noción de libertad asume que las personas son seres aislados, cuyo principal interés es actuar con los menores obstáculos posibles. Esto implica que el concepto de libertad, en las teorías de justicia, les ofrezca a los sujetos la oportunidad de calcular únicamente sus bienes individuales ${ }^{23}$. En este sentido, para Honneth, un orden legal y político solamente puede contar con la aprobación de los sujetos en cuanto satisfaga sus deseos individuales. Sin embargo, estos no tienen la oportunidad de examinar y actualizar su consentimiento respecto a las medidas políticas; puesto que, según el autor alemán, los individuos no participan en las revisiones de principios legales. En cambio, están conceptualmente limitados a un solo tipo de aprobación; a saber, que no tengan impedimentos para ser libres ${ }^{24}$.

En cuanto a las teorías de la libertad positiva, estas tienden a postular una noción de lo verdaderamente autónomo ${ }^{25}$. No obstante, así como la idea de libertad negativa conduce a una concepción de justicia que promueve un sistema social basado en el egoísmo, la idea de una autonomía moral ${ }^{26}$, "al determinar la libertad, deja de lado de manera totalmente artificial aquellas condiciones y formas institucionales que siempre deberían aparecer al iniciar la reflexión para llevarla a buen término"27. Es decir, para Honneth, este tipo de libertad rompe con las condiciones que permiten el mismo ejer-

22 Okochi, "Freedom and Institution: Theory of Justice as Hegelian 'Sttlichkeitslehre' in a Honneth's 'Das Recht der Freiheit"'. Ob. cit., 13.

23 En este punto, Honneth está pensando en autores tales como: Hobbes, Sartre y Nozick. Cfr. Honneth. El derecho de la libertad. Ob. cit., 39.

24 Honneth. El derecho de la libertad. Ob. cit., 36.

25 Cfr. "El núcleo de la idea de la libertad reflexiva lo constituye históricamente en una primera instancia la propuesta de diferenciar entre acciones autónomas y heterónomas. Con esta contraposición, cuyo precursor intelectual es Rousseau, el peso de la libertad individual fue desplazado de un solo golpe: una acción no puede considerarse libre solo por el hecho de que sea ejecutada en el mundo exterior sin que encuentre resistencias, sino únicamente en el momento en el que la intención de ejecutarla tenga su origen en la voluntad propia”. Honneth. El derecho de la libertad. Ob. cit., 48.

26 La idea de autonomía, al menos como se entiende en El derecho de la libertad, se explica de la siguiente manera: "Al igual que la idea de la libertad negativa, que siempre termina desembocando en una idea de la justicia que promueve un sistema social del egoísmo, al final de la idea de la autonomía moral siempre hay una concepción procedimental que sirve a un sistema social de cooperación o de deliberación democrática; sin embargo, en este segundo caso, el sistema mismo queda indeterminado en su contenido porque, por motivos conceptuales, la teoría no puede adelantar las decisiones que los sujetos autónomos solo pueden tornar por sí mismos". Honneth. El derecho de la libertad. Ob. cit., 58. Véase también: "The Fabric of Justice: On the Limits of Contemporary Proceduralism", en el libro The I in We. Ob. cit., 35-50.

27 Cfr. Honneth. The I in We. Ob. cit., 38; Coronado-Angulo, Razón instrumental, sociedad e instituciones. Una semblanza de Max Weber y la Escuela de Frankfurt. Ob. cit., 249. 
cicio de la libertad, puesto que asume que los sujetos se encuentran aislados de toda entidad e institución social; y, por más que se enfoquen en autorrealizarse en los mismos límites de su acción, conciben a los demás individuos como límites de su propia libertad ${ }^{28}$. Por tanto, este tipo de libertad no logra conciliar al individuo con el resto de la sociedad ${ }^{29}$.

\subsection{Libertad social}

Finalmente, Honneth formula un concepto de libertad que, a su parecer, es capaz de sustentar una teoría de la justicia que promueva el reconocimiento del ser humano por medio de instituciones sociales y concilie la pluralidad de valores y prácticas que presenta una sociedad ${ }^{30}$. En este caso, así como la libertad reflexiva expandió el concepto de libertad negativa, a través de la inclusión de la relación entre sujetos; la libertad social expande el concepto de libertad reflexiva en cuanto integra necesariamente a las instituciones ${ }^{31}$. Es decir, en este modelo, los deseos de los conciudadanos no son considerados como limitaciones o restricciones de las propias aspiraciones, sino que estas últimas se configuran a través de las aspiraciones de los demás ${ }^{32}$. Esto implica que las instituciones no son simples conglomerados,

28 Cfr. "Pero, a grandes rasgos, esta concepción de autenticidad no es lo suficientemente abarcadora, no incluye en grado suficiente la relación entre individuo y sociedad como para que pudiese por sí misma generar una idea independiente de justicia; por eso, tal vez sea correcto aquí hablar de un neutralismo o indiferencia respecto de cuestiones de la teoría de la justicia". Honneth. El derecho de la libertad. Ob. cit., 61. Sobre todo, Honneth no está de acuerdo con las teorías de la justicia que buscan una distribución de bienes, puesto que asumen que los individuos únicamente buscan sus bienes personales sin tomar en cuenta a los demás. Cfr. Honneth. The I in We. Ob. cit., 37-40.

29 Coronado, "La libertad como condición de la justicia según Axel Honneth". Cit., 155.

30 Cfr. "Claramente, incluso el modelo alternativo de justicia que tengo en mente debe comenzar por reconocer la idea normativa de que todos los miembros de las sociedades modernas deben poseer las mismas capacidades y condiciones para la autonomía individual. Lo que distingue a esta concepción alternativa no es, pues, su núcleo moral, sino sus implicaciones materiales. Todo gira en torno a cómo entendemos la promoción social de la autonomía, en cuyo papel crucial coinciden ambas partes. Mientras consideremos la libertad como algo que todos los individuos pueden lograr por sí mismos, basta con asumir que los bienes individualmente disponibles son el material de la justicia. Con la ayuda de estos bienes, las personas son capaces de crear un espacio para la consecución de sus planes de vida libremente elegidos". Honneth. The I in We. Ob. cit., 46. Traducción propia.

31 Cfr. Okochi, "Freedom and Institution: Theory of Justice as Hegelian 'Sttlichkeitslehre' in a Honneth's 'Das Recht der Freiheit”. Ob. cit., 14.

32 Cfr. "También los distintos conceptos de libertad reflexiva, al igual que la idea de la libertad negativa, condujeron a ideas específicas en cada caso respecto de cómo había que abordar metódicamente la cuestión de la justicia social. Si esta conexión era tan clara en el 
sino que son necesarias para el ejercicio de la libertad. La libertad social implica aceptar varias formas de reconocimiento institucionalizadas que proveen de fundamento, espacio y telos para su autorrealización:

"Cuando los individuos sienten que sus intenciones y sus propósitos son totalmente apoyados y apreciados en un orden social, entonces más van a querer desenvolver sus personalidades para alinear sus objetivos con los de otros actores sociales y, crucialmente, para asumir voluntariamente las obligaciones y sus deberes, que sus roles sociales requieren de ellos, más que experimentarlo como cargas impuestas externamente" 33 .

De aquí que la libertad social deba ser comprendida como aquella capaz de conciliar los intereses de los sujetos. Más aún, estas instituciones de reconocimiento deben, según Honneth, ser diseñadas con anterioridad a los sujetos, dado que estas funcionarán como mecanismos y canales para permitir el ejercicio de una libertad social. En ese sentido, cuando Honneth afirma que las instituciones deben preceder a los individuos, se está refiriendo a lo que explica en su obra, The I in We, en relación con la noción de justicia que él desea desarrollar. Sobre todo, porque siguiendo a su maestro Hegel defenderá que el mutuo respeto y reconocimiento por parte de los otros es la base tanto del autorrespeto personal como de la justicia en todas las esferas sociales propuestas por Honneth. En sus palabras: "Pero si eliminamos esta premisa, es decir, si podemos concebir el material de la justicia ya no en términos de bienes intercambiables, sino como relaciones sociales recíprocas, esto también afecta las condiciones básicas del procedimentalismo. Ya no podemos imaginarnos a los agentes deliberantes lidiando con algo que

ámbito de la primera idea del pensamiento de su autonomía, en el dominio del segundo ideal de libertad aparece, en un primer momento, como opaca: con la idea de la autonomía y el concepto de la autorrealización aparecen aquí al menos dos ideales de libertad enfrentados, cuyas concepciones de justicia implícitas a duras penas pueden tener un denominador en común". Honneth. El derecho de la libertad. Ob. cit., 57. A lo que agrega: "El contenido que rellena lo que ha de constituir un orden justo es aquí menos un asunto de los sujetos cooperantes que en el caso del ideal de autonomía, puesto que el teórico sabe naturalmente, al menos a grandes rasgos, a qué están supeditados socialmente los sujetos cuando se los faculta a autorrealizarse. A diferencia del procedimentalismo de aquellas concepciones de la justicia, que se originan a partir de la suposición de la libertad como autodeterminación, las ideas de justicia orientadas hacia el ideal de la autorrealización están por lo general elaboradas sustancialmente; si bien no deben anticipar los objetivos o la dirección del proceso de articulación individual, puede, sí, presentar a partir de conocimiento externo las condiciones sociales a las que está supeditado el individuo en este proceso". Honneth. El derecho de la libertad. Ob. cit., 59. Véase también: Honneth, La lucha por el reconocimiento. Ob. cit., 15-44; Honneth, The I in We. Ob. cit., 3-31; Okochi, "Freedom and Institution: Theory of Justice as Hegelian 'Sttlichkeitslehre' in a Honneth's 'Das Recht der Freiheit”. Ob. cit.

33 McNay, "Social Freedom and Progress in the Family". Ob. cit., p. 173. Traducción propia. 
pueden controlar libremente de acuerdo con sus propias concepciones de la justicia. Las relaciones de reconocimiento, que han demostrado ser las condiciones decisivas de la autonomía personal, no consisten en material que pueda asignarse a voluntad. No podemos colocarnos en una posición frente a estos 'bienes' en la que somos los tomadores de decisiones y presidimos su justa organización o distribución equitativa. Estas relaciones de reconocimiento representan, en cambio, fuerzas históricamente contingentes que influyen en nosotros detrás de nuestras espaldas. Querer desprendernos de ellos para poder verlos es abrigar una ilusión tan vacía y ociosa como el deseo de moldearlos como nos plazca" 34 .

En otras palabras, el reconocimiento al interior de las instituciones debe preceder a la libertad de los individuos autónomos y atomísticos ${ }^{35}$, porque cuando no se propicia la dependencia entre sujetos, las formas sociales pueden provocar la humillación y la negación de la dignidad humana ${ }^{36}$. Por lo tanto, si se quiere construir una teoría de la justicia a partir de una noción de libertad social, es preciso aplicar ciertos principios de reconocimiento a las instituciones y que estas ayuden a los individuos a considerarse como parte de un conjunto social, en donde se concilien sus deseos y aspiraciones ${ }^{37}$.

34 Honneth. The I in We. Ob. cit., 42-43. Traducción propia.

35 Cfr. Honneth. El derecho de la libertad. Ob. cit., 68-69.

36 Cfr. Honneth, A. (2004). "Recognition and Justice: Outline of a Plural Theory of Justice". Acta Sociológica, 47 (4)", 354. A lo que Honneth agrega: "Los sujetos sólo pueden atribuirse unos a otros un valor normativo, a la luz del cual son capaces de valorarse a sí mismos, si ambas partes acuerdan un principio moral que pueda servir como fuente de sus atribuciones y enunciados recíprocos. Ninguna relación de reconocimiento, ni siquiera aquellas relaciones pasadas en las que los sujetos se respetaron entre sí como no iguales, puede prescindir de una norma mutuamente acordada. Estos principios compartidos funcionan para asegurar que se pueda desarrollar y preservar una praxis de reconocimiento recíproco. Con estos fundamentos normativos de todo reconocimiento, sin embargo, nuestra teoría alternativa de la justicia posee algunos criterios iniciales para juzgar las instituciones y políticas existentes. Después de todo, las demandas hechas por estos principios morales coinciden con las condiciones bajo las cuales los sujetos idealmente alcanzan una medida de autoestima; por lo tanto, podríamos decir tentativamente que sería 'justo' instalar y equipar socialmente una esfera social existente como lo exige la norma subyacente de reconocimiento". Honneth. The I in We. Ob. cit., 47. Traducción propia.

37 Cfr. Honneth. "Recognition and Justice...". Ob. cit., 354. "Si, no obstante, entendemos esta clase de libertad social como el núcleo de todas nuestras ideas de libertad, frente al cual todas las otras ideas de libertad aquí tratadas se comporten de manera derivada, entonces, siguiendo a Hegel, tenemos que concluir también en una revisión de nuestras concepciones de justicia tradicionales: lo que en las sociedades modernas significa 'justo' no puede medirse simplemente por el hecho de que todos los miembros de una sociedad posean o no libertades negativas o reflexivas ni en qué extensión lo hagan, sino que debe antes satisfacer el patrón de otorgar a estos sujetos en igual medida la oportunidad de participar en instituciones de reconocimiento. Migra así al centro de la idea de la justicia social la noción de que determinadas 
Además, con respecto a la capacidad de la libertad social para otorgar una respuesta no individualista a la pluralidad de valores, Honneth afirma que la instauración del reconocimiento a nivel institucional permite asegurar que los individuos se desenvuelvan plenamente, pero con la conciencia de que pertenecen a un entramado de prácticas sociales muy distintas. Como indica Cecilia Coronado: "Bajo la influencia de prácticas institucionalizadas los sujetos aprenden a orientar sus motivos hacia objetivos internos" 38 . Es decir, si se reconoce que existen intereses y deseos muy diversos entre los individuos, las instituciones pueden armonizar las diferencias; aspecto que ni la libertad negativa ni la reflexiva son capaces de lograr, ya que, su definición se basa en una noción individualista de los sujetos $^{39}$. Particularmente, la libertad social permite formular la teoría sobre la justicia de Honneth porque esta no depende únicamente de principios normativos a priori basados en una repartición de bienes ${ }^{40}$, sino que se estructura a partir de un análisis social en el cual se toma en cuenta la pluralidad de valores y prácticas presentes en la realidad, pero que, gracias a las instituciones, pueden conciliarse y favorecer el reconocimiento entre los distintos sujetos. Sin embargo, conviene aclarar las características de dichas instituciones y de qué manera son capaces de fomentar las relaciones entre individuos; más aún, porque, para Honneth: "[Su] concepción alternativa entiende la autonomía individual no como un asunto monológico sino como un asunto intersubjetivo. Los individuos logran la autodeterminación aprendiendo, dentro de relaciones de reconocimiento recíproco, a ver sus necesidades, creencias y habilidades como dignas de articulación y búsqueda en la esfera pública. Esto no obvia la justicia distributiva, pero sí la degrada del principio decisivo de la justicia a una variable dependiente en las relaciones de reconocimiento. La concepción alternativa intersubjetiva de la autonomía transforma fundamentalmente la arquitectura de la teoría de la justicia. Esto no solo es cierto para su material, sino también para su princi-

instituciones, de mucho contenido normativo y, por lo tanto, denominadas 'éticas', necesitan de la garantía jurídica, de la protección estatal y del apoyo de la sociedad civil; solo en un juego en el que se reparten las tareas al derecho, la política y lo público social pueden mantenerse vivos aquellos aparatos institucionales a los que los miembros de una sociedad deben las distintas facetas de su libertad intersubjetiva y así, globalmente, la cultura de la libertad". Honneth. El derecho de la libertad. Ob. cit., 88.

38 Coronado-Angulo, Razón instrumental, sociedad e instituciones. Una semblanza de Max Weber y la Escuela de Frankfurt. Ob. cit., 252.

39 Cfr. McNay, "Social Freedom and Progress in the Family". Ob. cit., 172.

40 A diferencia de las teorías de justicia distributiva, Honneth no desea construir desde cero principios de justicia, sino que busca reconstruirlos a partir de los procesos históricos de las relaciones de reconocimiento que se encuentran entre los individuos y las instituciones. Cfr. Honneth. The I in We. Ob. cit., 42-47. 
pio de forma y relación de agente (Akteursbezug), todos los cuales adquieren una nueva definición tan pronto como captamos la libertad individual como resultado de relaciones de reconocimiento" 41 .

Es decir, la teoría de la justicia que busca defender Honneth debe exigir el autorespeto en las tres esferas de reconocimiento; sin embargo, no pueden apoyarse únicamente en las intenciones de los sujetos, sino que deben apoyarse en la cooperación de las instituciones. No obstante, cuando Honneth afirma que la libertad social no se basa únicamente en principios a priori, se está refiriendo, al igual que en la formulación de la teoría de la justicia, a que él utiliza la misma metodología histórica y crítica para analizar, a partir de la realidad social, el modo en que cada esfera cumple con la aspiración de reconocimiento social, sobre todo, porque retoma a diversos sociólogos para complementar lo dicho por Hegel ${ }^{42}$. Por tanto, es cierto que Honneth parte de una autorrealización de los sujetos en la que solo hay un reconocimiento anterior a cualquier práctica o normativa. Esto, de hecho, es prueba de las deficiencias que posee la teoría de Honneth. Sobre todo, porque cae en una circularidad al decir que parte de realidades sociales y, sin embargo, estas mismas realidades ya están determinadas por normas y valores intrínsecos basados en el reconocimiento mutuo ${ }^{43}$.

41 Honneth. The I in We. Ob. cit., 46. Traducción propia.

42 Cfr. Honneth. El derecho de la libertad. Ob. cit., 20. Es más, en una entrevista, Honneth enfatizó en la importancia que la sociología posee en el análisis de la sociedad. Sin negar su influencia hegeliana, destaca que los aportes sociológicos son necesarios para comprender a profundidad las patologías sociales. Cfr. Petersen, A. y Willig, R. (2002). "An interview with Axel Honneth: The Role of Sociology in the Theory of Recognition". European Journal of Social Theory, 5 (2). Ahora bien, también es importante destacar que, en cierto sentido, Honneth parte de normas intrínsecas y antropológicas que son condición de posibilidad para la formulación de una teoría de la justicia. Él mismo, siguiendo a su maestro Hegel, da por sentado que el "reconocimiento mutuo", "quiere decir, en primer lugar, solo la experiencia recíproca de verse confirmado en los deseos y metas de la contraparte en cuanto la existencia de estos representa una condición de la realización de los propios deseos y las propias metas; bajo la condición de que ambos sujetos reconozcan la necesidad de complementariedad de sus respectivas metas, es decir, de que vean en la contraparte el otro de sí mismos, se amplía la libertad". A lo que Honneth agrega: "Hegel establece el nexo con el concepto de institución o de medio al concebir como condición social de tal reconocimiento de la complementariedad de metas y deseos la existencia de prácticas de comportamiento normadas: ambos sujetos deben haber aprendido tanto a articular sus respectivas metas de manera inteligible para su contraparte como a entender sus enunciaciones adecuadamente antes de poder reconocerse mutuamente en su dependencia uno del otro". Honneth. El derecho de la libertad. Ob. cit., 67-68.

43 Cfr. Honneth. La lucha por el reconocimiento. Ob. cit.; Honneth. The I in We. Ob. cit., 35-50; Okochi, "Freedom and Institution: Theory of Justice as Hegelian 'Sttlichkeitslehre' in a Honneth's 'Das Recht der Freiheit”. Ob. cit., 17. 
Ahora bien, lo que cabe aclarar es por qué Honneth se atreve a proponer el mercado como esfera de libertad social y como condición de posibilidad para la formulación de su teoría institucional de la justicia ${ }^{44}$.

\section{Esferas de libertad social}

La tesis de Honneth consiste en afirmar que cada esfera posee ciertos principios de libertad social determinados. Estas tres esferas -(i) relaciones personales, (ii) mercado y (iii) vida política- representan el material empírico para la reconstrucción de su teoría de la justicia ${ }^{45}$. Aunque me enfocaré, principalmente, en la esfera del mercado, explicaré de modo general las tres esferas para evidenciar cómo están inseparablemente vinculadas entre sí. $\mathrm{Al}$ respecto, hay que considerar que la reconstrucción normativa de estas tres esferas busca recordarnos que cada una de ellas se encarga de fomentar, de distinta manera, el reconocimiento de los individuos en un contexto social $^{46}$.

\subsection{Relaciones personales}

En el caso de las relaciones personales, Honneth menciona que la familia representa de un modo especial la base de la libertad social y afirma que es el epítome de las virtudes democráticas. La importancia de dicha sociedad radica en que en ella se inculcan ciertas virtudes democráticas esenciales, tales como la responsabilidad, la obligación o la tolerancia. De hecho, en opinión de Honneth, las teorías liberales de la justicia deben considerar seriamente la posibilidad de ayudar a las familias a prosperar ${ }^{47}$. Incluso, afirma que las relaciones familiares de mutua dependencia, en su forma más pura, constituyen el tipo de lazo necesario para la realización de la libertad social. Sin embargo, esta esfera ha sufrido cambios desde la Modernidad y, por ello, el amor se ha democratizado, forjando relaciones individualistas al interior de la familia; aunque, por otro lado, los miembros de las familias se reconocen los unos a los otros como parte de una comunidad solidaria conformada por lazos sanguíneos. Esto se debe a que la democratización de los lazos filiales, al volverlos horizontales, genera un

44 Cfr. Coronado-Angulo. Razón instrumental, sociedad e instituciones. Una semblanza de Max Weber y la Escuela de Frankfurt. Ob. cit., 283.

45 Cf. McNay. "Social Freedom and Progress in the Family". Cit., 171.

46 Cfr. ibídem, 173.

47 Cfr. ibídem, 174-175. 
nuevo modelo de reciprocidad entre los integrantes de la familia ${ }^{48}$. En otras palabras, para Honneth, el liberalismo ha modificado las relaciones al interior de la familia, provocando que ya no se conciban de modo jerárquico, sino igualitario. Sin embargo, Honneth postula que esta democratización es, precisamente, lo que les permite a los sujetos manejar la transición a la vida pública, de manera que la misma comunidad de solidaridad podría ser traducida en medidas económicas y políticas ${ }^{49}$. Por tanto, esta esfera de libertad social se presenta como el primer escalón para el resto de las instituciones elegidas por Honneth, puesto que se encarga de propiciar los valores básicos de reconocimiento ${ }^{50}$.

\subsection{El mercado}

Honneth afirma que parecería absurdo concebir "el sistema de la acción económica mediada por el mercado como una esfera de libertad"51. Más aun cuando la economía capitalista de los últimos dos decenios se ha opuesto totalmente a lo que implica la institucionalización de la libertad social. En ese sentido, el mercado es un caso particular porque Honneth expresa que, de hecho, carece de las características necesarias para pertenecer a una esfera de libertad social, ya que no genera, en principio, una instancia donde los sujetos puedan reconocerse mutuamente como seres libres. Esto se debe a que "durante los últimos dos decenios la economía capitalista fue adquiriendo una forma social que se opone totalmente a lo asociado con las obligaciones de roles ensambladas y, con ello, a la institucionalización de la libertad social" 52 . Por tanto, no hay una relación directa de reconocimiento entre individuos. Con esa premisa, Honneth compara los valores familiares con el mercado y recurre a la construcción moral del sistema económico ${ }^{53}$.

48 Coronado-Angulo. Razón instrumental, sociedad e instituciones. Una semblanza de Max Weber y la Escuela de Frankfurt. Ob. cit., 258.

49 Honneth. El derecho de la libertad. Ob. cit., 228-229.

50 Es claro que cada una de las tres esferas es susceptible a una serie de críticas y reacciones en contra. En el caso de la familia, una autora que trata a fondo las principales críticas es: McNay. "Social Freedom and Progress in the Family". Cit. Sin embargo, por lo que compete a este escrito, no ahondaré en ellas.

51 Es necesario destacar que Axel Honneth no define lo que es el mercado; sin embargo, sí describe y explica que entiende al mercado como expresión del sistema económico capitalista de las sociedades Occidentales. Honneth. El derecho de la libertad. Ob. cit., 232.

52 Cfr. Honneth. El derecho de la libertad. Ob. cit., 232.

53 Es necesario aclarar lo que Honneth concibe como moralidad y eticidad, basándose en Hegel. En ese sentido: "Para Hegel, de la multiplicidad de formas de vida éticas solo se aceptaba, en su Filosofía del Derecho, bajo el concepto de 'eticidad' aquello que probadamente pudiera servir para ayudar a realizar los valores e ideales generales de las sociedades moder- 
Esto porque, a diferencia de las relaciones personales, donde los participantes reconocen al otro en la idea normativa de "amor", el mercado capitalista puede ser considerado como una institución de libertad social si se asume su capacidad para establecer y expandir el reconocimiento en su mecanismo institucional de consumo y producción ${ }^{54}$.

Ahora bien, dado que el mercado todavía no es una esfera de libertad social, se requiere, según Honneth, realizar un análisis histórico del capitalismo para comprender cómo se fue desarrollando a lo largo del tiempo. En dicho estudio, la aparición del homo oeconomicus, el empresario egoísta como modelo de comportamiento, muestra que empiezan a aparecer cambios beneficiosos, pero también dañinos en la sociedad ${ }^{55}$. Por tanto, el propósito de Honneth es mostrar que el mercado económico depende de bases morales y éticas; pero que se entienden más como normas intrínsecas al mercado que extrínsecas. Es decir, la misma existencia de tales normas posibilita que el mercado sea una esfera de libertad social ${ }^{56}$. Honneth afirma que, "como cualquier otra esfera social, el mercado también depende del consentimiento moral de sus participantes, de modo que su existencia no puede ser explicada sin hacer referencia a las normas suplementarias que legitiman el mercado en los ojos de los actores económicos" ${ }^{\text {7 }}$. En otras palabras,

nas; todo lo que contradijera estos requisitos normativos, todo lo que representara valores particulares o encarna ideales retrógrados, ni se le consideraba digno de convertirse en objeto de la reconstrucción normativa. Hegel, en cambio, eligió en primer lugar este concepto, en contra de la tendencia imperante en la filosofía moral, para llamar la atención acerca de aquella red de rutinas y obligaciones en las que estaban insertas las actitudes morales no ya en forma de orientación hacia principios sino en forma de prácticas sociales; para él, que en su método seguía siendo aristotélico en contextos de la filosofía práctica, no cabía duda de que los hábitos practicados intersubjetivamente -y no las convicciones cognitivas- conformaban el ámbito de la moral. No obstante, Hegel no quería que su concepto de 'eticidad' se entendiera como una simple descripción de las formas de vida existentes; ya el procedimiento que eligió, aquella 'reconstrucción normativa' anteriormente descripta, deja claro que intentaba proceder de manera mucho más selectiva, tipificadora y normativa que lo que le permitía el positivismo aristotélico". Honneth. El derecho de la libertad. Ob. cit., 21. Véase también: Honneth, A., \& Farrell, J. (1997). "Recognition and Moral Obligation". Social Research, 64 (1); Jütten, T. "Is the Market a Sphere of Social Freedom?". Ob. cit.

54 Cfr. Honneth. El derecho de la libertad. Ob. cit., 234.

55 Cfr. ibídem, 238.

56 Jütten. "Is the Market a Sphere of Social Freedom?" Ob. cit., 192. A lo que agrega: "Decir que el mercado es una esfera de libertad social es decir que es una esfera de acción social en la que los actores individuales se 'completan' en el sentido de que la satisfacción de los deseos de los demás es una condición previa para la satisfacción de los suyos. El reconocimiento mutuo de la dependencia mutua es una forma de libertad, porque los actores individuales reconocen en las instituciones del mercado los mecanismos a través de los cuales se hace posible la satisfacción de los deseos de todos". Jütten, T. "Is the Market a Sphere of Social Freedom?" Ob. cit., 188. Traducción propia.

57 Honneth. El derecho de la libertad. Ob. cit., 184. 
el mercado solo puede cumplir su función si integra armoniosamente las actividades económicas individuales basadas en relaciones de solidaridad que preceden a todo contrato y obligan a los actores económicos a tratarse de manera correcta y justa ${ }^{58}$.

Si bien la tesis de Honneth suena utópica, él afirma que es posible llevar esto a cabo mediante las corporaciones, pues estas permitirían desarrollar un consentimiento moral en el mercado económico a partir de ciertos criterios específicos ${ }^{59}$. En primer lugar, el interés individual constitutivo del comportamiento del mercado tiene que ser capaz de satisfacer la condición necesaria de explicar que este funciona como medio para complementar cada proyecto individual. En segundo lugar, las corporaciones deben reflejar institucionalmente los reclamos subyacentes, asegurándose de que los participantes estén al tanto de tales demandas. En tercer lugar, los actores económicos deben reconocerse como miembros de una comunidad cooperativa, antes de que le puedan ceder a otro el derecho de maximizar su utilidad individual ${ }^{60}$.

Honneth afirma que las corporaciones poseen un papel sumamente importante en la formación de las actitudes éticas de sus miembros. Incluso sostiene que la familia es la primera raíz ética del Estado y el mercado, la segunda ${ }^{61}$. Es más, solamente a través de corporaciones, los sujetos pueden involucrarse conscientemente en una cooperación social. Especialmente en el contexto actual, se habla de comportamiento moralizante cuando los ciu-

58 Cfr. ibídem, 181.

59 Es necesario destacar que Honneth retoma la concepción de corporación dada por Hegel. En ese sentido: las corporaciones son organizaciones creadas por seres humanos; son entidades económicas que caben dentro de la economía política; poseen miembros basados únicamente en sus capacidades mercantiles. Pero sobre todo, al incluir seres humanos, las corporaciones están inextricablemente ligadas a una ética. Cfr. Klikauer, T. (2015). Hegel's Moral Corporation. Palgrave Macmillan UK, 18. No obstante, si bien hay una gran distinción entre lo que Hegel consideraba como corporación en el siglo XIX, las similitudes entre ambas justifican que Honneth las asuma. Más aún cuando argumenta que las corporaciones del mercado poseen una ética intrínseca. En palabras de Honneth: "Si retomo este esbozo hegeliano hoy, doscientos años después, lo hago con conciencia de que no solo las circunstancias de la sociedad sino también las condiciones de argumentación filosófica se han transformado enormemente. Una simple reactivación de la intención y del razonamiento de la Filosofía del Derecho es algo imposible hoy. Por un lado, la realidad social de entre cuyas instituciones y prácticas había que mostrar cuáles gozan del estatus de facticidad moral es radicalmente distinta a la de la sociedad industrial incipiente, monárquica constitucional de principios del siglo XIX; todas las condiciones institucionales, en cuya estabilidad normativa Hegel aún podría confiar sin reparos, han perdido su forma original como consecuencia de una modernización acelerada, llamada 'reflexiva', y, en gran parte, han sido reemplazadas por aparatos y organizaciones nuevas, mucho más flexibles". Honneth. El derecho de la libertad. Ob. cit., 15.

60 Cfr. Honneth. El derecho de la libertad. Ob. cit., 232-233.

61 Cfr. ibídem, 340. 
dadanos deben atender a razones ecológicas o sociales en el momento en que deciden comprar algo ${ }^{62}$. Como bien señala Cecilia Coronado: "En estas tendencias de la moralización de los mercados vuelve a abrirse la perspectiva de una reciprocidad entre los consumidores y las compañías, en torno a la realización de la libertad social en la esfera de consumo"63. No obstante, Honneth es consciente de que en la realidad aún no existe una armonización en la esfera del mercado debido a la lógica de consumo existente, ya que, a pesar de que se quiera moralizar el comportamiento de las compras a partir de un consentimiento de las implicaciones, prevalece la mentalidad del consumismo privado ${ }^{64}$.

En resumen, Honneth cree que cuando los miembros de una corporación están preocupados por la regulación del comportamiento del mercado, y por ello, consideran los intereses de los otros participantes del mercado, se requiere que los sujetos se unan en torno a un principio de cooperación y solidaridad. Sin embargo, en este punto es fundamental apelar al rol democrático de los ciudadanos y del Estado, puesto que, hasta el día de hoy, al mercado le hace falta un fortalecimiento de su institucionalidad por medio de una legitimización de sus prácticas. En ese caso, la vida política jugará un papel sumamente importante.

\subsection{Vida política}

Como se ha mencionado a lo largo del texto, el objetivo de Honneth es la elaboración de otro tipo de teoría de la justicia, en la cual el robustecimiento de la institucionalidad de cada esfera social implique un reconocimiento de la dignidad humana ${ }^{65}$. En esa línea, la esfera política debe

62 Cfr. Coronado-Angulo, Razón instrumental, sociedad e instituciones. Una semblanza de Max Weber y la Escuela de Frankfurt. Ob. cit., 267.

63 Ídem.

64 Es importante destacar que, a lo largo del libro El derecho de la libertad, Honneth hace referencia a otros aspectos morales del mercado a partir de un análisis histórico desde la modernidad. No obstante, retomo únicamente los aspectos que me permiten proponer al mercado como una posible esfera de libertad social. Si se quiere profundizar más al respecto, véase: Honneth. El derecho de la libertad. Ob. cit., 232-262.

65 De hecho, en la esfera política Honneth afirma: "[...] vamos a tener que distanciarnos del modelo de la Filosofía del Derecho hegeliana si queremos emprender la reconstrucción normativa de aquella tercera esfera que, a su vez, se analiza adecuadamente cuando se la concibe como una encarnación de la libertad social: de la institución de la vida pública democrática como un espacio social intermedio en el cual se construirán entre los ciudadanos, en oposición deliberativa, las convicciones que puedan ser aprobadas por todos, a las que a continuación se ceñirá la legislación parlamentaria conforme a procedimientos del Estado de derecho". Honneth. El derecho de la libertad. Ob. cit., 339. 
asumir lo siguiente: "Por eso, la esfera política de la vida pública no debe entenderse, como es frecuente hoy en las teorías de la democracia, como una corte suprema en la que en último término se decide de forma autónoma acerca de cómo deben ser las condiciones, que se deben regular en sintonía con el Estado de Derecho, en las otras dos esferas de acción; la relación entre las tres esferas es mucho más complicada, pues la realización de la libertad social en la vida pública democrática está, por su parte, ligada al requisito de que los propios principios estén realizados, en alguna medida, también en las esferas de las relaciones personales y de la economía de mercado"66.

Es decir, la esfera política debe hacer referencia al mutuo reconocimiento de los individuos para propiciar un espacio social intermedio en el que construirán entre los ciudadanos, las convicciones que puedan ser aprobadas por todos ${ }^{67}$. Específicamente, la conciliación con las otras dos esferas de libertad es lo que le permite a una democracia liberal propiciar la libertad social, puesto que genera un espacio de acción donde los individuos pueden poner en práctica el reconocimiento y los valores de las relaciones personales y del mercado. Los individuos proceden de dos esferas donde se propicia el amor y la solidaridad y, lo que es más importante, la vida política implica un compromiso entre los ciudadanos, que siendo tan distintos entre sí, son conscientes de que lo político es su punto en común ${ }^{68}$.

Más aún, para que la construcción democrática se lleve a cabo, es preciso que los ciudadanos cumplan con las acciones de cada esfera, que ejecuten prácticas sociales y que, principalmente, el Estado de Derecho garantice esa libertad ${ }^{69}$. Después de todo, mientras más libertad social sea posible en las relaciones personales y en el mercado, el desenvolvimiento de los ciudadanos en la formación de la voluntad pública será más igualitario, libre y confiado. Precisamente por eso, los que deliberan y buscan un acuerdo en su comunidad no pueden ser indiferentes a las relaciones sociales que se producen en las otras dos esferas.

Por tanto, sin una brújula moral, la libertad de la formación de la voluntad democrática se separará de las otras libertades sociales que han formado una red institucional de dependencias recíprocas. Para Honneth, cualquier teoría democrática que no logre conciliar todos los criterios normativos de las esferas sociales con la realidad, no podrá comprender el significado de la esfera política como una autoridad reflexiva entre las otras

66 Honneth. El derecho de la libertad. Ob. cit., 340.

67 Cfr. ibídem, 339.

68 Cfr. Coronado-Angulo, Razón instrumental, sociedad e instituciones. Una semblanza de Max Weber y la Escuela de Frankfurt. Ob. cit., 279.

69 Cfr. Honneth. El derecho de la libertad. Ob. cit., 338. 
esferas de acción ${ }^{70}$. Sobre todo, porque la vida política ha asegurado la atención compartida del resto de las instituciones, pues cada una tiene que ser concebida como parte del reconocimiento de la responsabilidad compartida que poseen los individuos. Estos lazos de solidaridad son, para Honneth, lo que permite hablar de una comunidad a partir de una libertad social encarnada por las tres esferas ${ }^{71}$.

\section{Construcción de una teoría institucional de justicia}

Honneth cae en cuenta de que las teorías de la justicia contemporáneas, al considerar las nociones de justicia de Locke y Kant, yerran al asumir que sus principios normativos deben ser independientes de las instituciones políticas y sociales ${ }^{72}$. Incluso, Honneth menciona que, aunque Rawls y Habermas reconstruyen sus normas a partir de las sociedades democráticas liberales, no le dan ninguna importancia a lo que instituciones concretas pueden aportar al fomento de la justicia ${ }^{73}$. Particularmente, al apoyarse en nociones individualistas de libertad, Honneth piensa que es imposible hablar de justicia en el contexto actual ${ }^{74}$. Es más, siendo consciente de la

70 Cfr. ibídem, 338.

71 Cfr. ibídem, 339.

72 Cfr. Okochi, "Freedom and Institution: Theory of Justice as Hegelian 'Sttlichkeitslehre' in a Honneth's 'Das Recht der Freiheit"'. Ob. cit., 1.

73 En este punto, Honneth menciona a algunos autores que sí se han interesado por el fortalecimiento de ciertas instituciones, tales como: Michael Walzer, David Miller y Alasdair McIntyre.

74 Honneth afirma, retomando a Hegel, "que las propuestas de construcción de la justicia fracasan porque prometen a los sujetos como colaboradores en tales procesos una libertad que ellos no podrían obtener sin participar en instituciones que ya son justas. Sin embargo, las teorías modernas de la justiciar pueden creerse a salvo del aprieto en que así caen porque presuponen conceptos de libertad individual que no dan cuenta adecuadamente de su dependencia de la mediación objetiva, del cumplimiento en la realidad. Si para alcanzar la libertad es suficiente el actuar, ya sea sin limitación externa o en actitud reflexiva, los sujetos entonces pueden ser pensados como suficientemente libres ya antes de toda integración en un orden social. Si, en cambio, se concibe al sujeto verdaderamente 'libre' solo allí donde sus metas son cumplidas o realizadas por la realidad misma, entonces la relación entre proceso legítimamente y justicia social debe invertirse en cierta medida: primero hay que poder pensar a aquel sujeto como integrado en estructuras sociales que garantizan su libertad antes de que pueda ser colocado como ser libre en procesos que velan por la legitimidad del orden social". Honneth. El derecho de la libertad. Ob. cit., 83. De nuevo, Axel Honneth no da una definición de lo que él concibe como justicia, sino que enuncia cómo es posible una elaboración de una teoría de la justicia. Esto por supuesto es un serio problema metodológico en la obra de Honneth. Cfr. Okochi, "Freedom and Institution: Theory of Justice as Hegelian 'Sttlichkeitslehre' in a Honneth's 'Das Recht der Freiheit"'. Ob. cit. 
pluralidad de prácticas sociales, propone las tres esferas, donde cada una fomenta diversos valores. Esto quiere decir que, para elaborar una teoría de la justicia, es necesario considerar que nuestros deseos, inclinaciones y normas morales no son independientes de la sociedad ni de las instituciones, sino que se forman en ellas. Según Honneth, las teorías de justicia actuales son incapaces de ver el potencial que posee el mercado y afirma que basarse en definiciones individualistas de libertad solo promueve actitudes egoístas en los sujetos cuando, en realidad, la esfera económica es crucial para hablar de una sociedad justa.

\subsection{Críticas en contra del mercado como esfera de libertad social}

En la teoría de Honneth, se encuentran diversas críticas a la definición de libertad social ${ }^{75}$ enfocadas en la elección de sus principios normativos ${ }^{76}$, e incluso, en la elección de las esferas que propone como aquellas capaces de propiciar libertad ${ }^{77}$. No obstante, en este artículo se pondrá de manifiesto en qué medida es necesario que el mercado sea una esfera de libertad social, para hacer posible la elaboración de una teoría institucional de la justicia. Si bien es cierto que el mercado no es aceptado por Honneth como una esfera de libertad social per se, el pensador considera que está en potencia

75 McNay. "Social Freedom and Progress in the Family". Ob. cit.; Lysaker, O. (2017). "Institutional Agonism: Axel Honneth's Radical Democracy”. Critical Horizons, 18 (1).

76 En cuanto a diversas críticas dirigidas a la propuesta de Axel Honneth, véase: McNay, L. (2008). "The Trouble with Recognition: Subjectivity, Suffering, and Agency”. Sociological Theory, 26 (3); Freyenhagen, F. (2015). "Honneth on Social Pathologies: A Critique". Critical Horizons, 16 (2); Lysaker. "Institutional Agonism". Ob. cit.; Haber, S. (2007). "Recognition, Justice and Social Pathologies in Axel Honneth's Recent Writings". Revista de ciencia politica (Santiago), 27 (2).

77 Cfr. "En este sentido, lo que significa 'dar a cada cual lo suyo' resulta para Hegel en cada caso solo a partir del sentido interno de prácticas de acción ya establecidas. Dado que este sentido, o este significado, resulta por otra parte únicamente a partir del valor ético que posee la respectiva esfera en la estructura entera de la sociedad, los patrones de la justicia solo pueden ser analizados haciendo uso de ideales que en cada sociedad están institucionalizados fácticamente: debe valer como 'justo' aquello que tiende en las distintas esferas sociales a promover un trato adecuado, 'justo' en el sentido del rol que se le destina realmente en la división ética de tareas de una sociedad". Honneth. El derecho de la libertad. Ob. cit., 18. Cfr. Islam, G. (2012). "Recognition, Reification, and Practices of Forgetting: Ethical Implications of Human Resource Management". Journal of Business Ethics, 111 (1); Okochi. "Freedom and Institution: Theory of Justice as Hegelian 'Sttlichkeitslehre' in a Honneth's 'Das Recht der Freiheit”. Ob. cit.; van Leeuwen, B. (2007). "A Formal Recognition of Social Attachments: Expanding Axel Honneth's Theory of Recognition”. Inquiry, 50 (2). 
de serlo a través del fortalecimiento de sus instituciones ${ }^{78}$. No obstante, es válida, en cierto sentido, la crítica de Timo Jütten en su artículo: "Is the Market a Sphere of Social Freedom?". Ahí Jütten señala que Honneth no está hablando directamente del mercado, ya que las relaciones de los miembros de una compañía no son mediadas directamente por mecanismos mercantiles ${ }^{79}$. Esto quiere decir que las preocupaciones y los rasgos morales y éticos que propician las corporaciones para fomentar el reconocimiento son intereses externos que ayudan a convertir al mercado en una esfera social, pero que no son propios de este. Además, aunque Honneth argumente a favor de las corporaciones para fortalecer el mercado, se enfrenta, principalmente, con un problema, a saber: que las mismas reglas del mercado, en general (por ejemplo, la competencia o la determinación de precios en la oferta y la demanda), entran en conflicto con las precondiciones de la libertad social, puesto que lo último que hacen es favorecer el reconocimiento de los demás individuos ${ }^{80}$. En la mayoría de los casos, el mercado funciona a partir de relaciones contractuales donde el cálculo respecto a los beneficios que se obtienen es lo relevante, no el reconocimiento entre los compradores $\mathrm{y}$ vendedores.

Sin embargo, si bien la crítica de Jütten pone de manifiesto una gran debilidad del mercado, Honneth busca robustecer las corporaciones precisamente porque piensa que estas funcionan como cursos de acción para fortalecer las relaciones entre los individuos dentro del mercado. Es claro que el mercado funciona maximizando utilidades individuales; de hecho, menciona Honneth, no posee intrínsecamente valores morales o éticos ${ }^{81}$. Empero, no se trata de que el mercado sea así, sino de que pueda convertirse en un espacio de libertad en donde se reconozca el simple hecho de que los individuos son seres humanos. Estos seguirán atendiendo a sus intereses individuales, y por lo pronto, a sus fines egoístas, eso es una rea-

78 "Honneth no se compromete con la idea inverosímil de que los mercados en las sociedades capitalistas de hoy son, de hecho, esferas de libertad social. Sin embargo, sugiere que la promesa de libertad social está implícita en las instituciones del mercado y que esta promesa explica la legitimidad del mercado a los ojos de los participantes del mercado. Sobre la base de esta sugerencia, una teoría crítica de la sociedad puede diagnosticar las desviaciones de la promesa implícita en la institución del mercado como desarrollos erróneos que afectan a las sociedades capitalistas de hoy". Jütten, T. "Is the Market a Sphere...”. Ob. cit., 188. Traducción propia.

79 Cfr. Jütten. "Is the Market a Sphere...". Ob. cit., 195.

80 Cfr. ibídem, 196.

81 Con respecto a este punto, basta con el análisis histórico y social que se realiza en $E l$ derecho de la libertad para comprender que incluso Honneth es consciente de los cambios que ha habido en el mercado y en el capitalismo. Recogiendo las posturas de Marx, Polanyi, Hegel y Durkheim, Honneth afirma que el funcionamiento de la economía se basa precisamente en la maximización de bienes individuales. Cfr. Honneth. El derecho de la libertad. Ob. cit., 232-233. 
lidad del mercado, pero esa constatación exige, precisamente, un mayor fortalecimiento de las instituciones ${ }^{82}$. En ese sentido, no es que el autor quiera moralizar el mercado, sino que desea humanizar el trabajo institucional. Es decir, aspira a que las instituciones logren que el trabajador y el empleador cooperen para alcanzar un mutuo reconocimiento y se consolide, así, una mayor conciencia respecto a la libertad social. Si la relación entre ambas partes en una corporación consiste en el reconocimiento del otro como condición de la propia libertad, entonces es posible implantar los valores comunitarios que el contexto social requiere ${ }^{83}$. Pero sobre todo, hay que tener en cuenta que el robustecimiento del mercado es necesario para la formulación de la teoría institucional de la justicia porque la justicia debe ser entendida a la luz de los valores que se propician en el ámbito social ${ }^{84}$. Es más, el concepto de justicia no puede ser entendido como desvinculado de los valores sociales, pues las prácticas sociales y las instituciones son "justas" solamente en la medida en que son capaces socialmente de realizar valores aceptados de manera general ${ }^{85}$. En ese sentido, el mercado posee mecanismos de discurso donde los actores adoptan la perspectiva de otros. Incluso en decisiones colectivas, al involucrarse en procesos de intercambio, sus intenciones no pueden ser meramente descritas como la suma de intereses individuales. A diferencia de las teorías que establecen solamente las condiciones de igualdad de oportunidad, Honneth apunta a una teoría en la cual las instituciones son aquellas que pueden propiciar un tipo de libertad social en vistas a una sociedad justa. Sobre todo, porque, como mencionaba Honneth, una sociedad es justa solamente si aceptamos que los individuos se necesitan los unos a los otros para desarrollarse y desenvolverse en cualquier contexto social ${ }^{86}$.

Ahora bien, la segunda crítica es fundamental porque muestra una excesiva esperanza, por parte de Honneth, en el mercado. Esta consiste en la observación que Jütten toma de G. A. Cohen, en ¿̇Por qué no el socialismo?, donde menciona que el mercado incita a sus participantes a desarrollar motivos de acción que son incompatibles con la libertad social. Es decir, los individuos dependen crucialmente del miedo y la avaricia y, además, en los

82 Hay autores como Douglas C. North que profundizan en los cambios institucionales a lo largo del tiempo en su libro (1995). Las instituciones, el cambio institucional, el desempeño económico. México. FCE, p. 16.

83 Cfr. Honneth. El derecho de la libertad. Ob. cit., 264.

84 Cfr. Coronado. "La libertad como condición de la justiciar según Axel Honneth". Ob. cit., 50 .

85 Cfr. Honneth. El derecho de la libertad. Ob. cit., 262-264.

86 Cfr. ibídem, 262. 
mercados hay una actitud de no reciprocidad ${ }^{87}$. Incluso señala que la deficiencia del mercado es provocada por sus preocupaciones meramente contractuales e instrumentales, y no de reconocimiento. En ese sentido, sería contradictorio afirmar que el mercado es una esfera de libertad social. Por el contrario, fomenta que los individuos sean todavía más egoístas. El mercado, por definición, apunta a maximizar los beneficios de cada individuo por separado y no exige que estos actúen en vistas a los beneficios de los demás y mucho menos por la justicia.

No obstante, es posible argumentar desde la teoría de Honneth -considerando la función que cumplen las compañías en el mercado y su preocupación por el impacto ambiental- que el consumismo y las relaciones meramente contractuales pueden ser mitigadas mediante el fortalecimiento institucional del mercado. De hecho, en este punto, es crucial recordar la inseparabilidad de las esferas, puesto que sin los valores comunitarios que aportan la familia y la vida política, el mercado se presenta como la esfera más frágil dentro de la teoría de Honneth. Sin embargo, tanto la integración familiar como la política aportan una noción de responsabilidad solidaria, basada en un reconocimiento mutuo que permite fortalecer la función de las instituciones. La esfera familiar aporta la primera instancia social y cultiva los lazos solidarios de la sociedad mostrando la dependencia que existe dentro de la familia ${ }^{88}$. Por otro lado, el papel de la esfera política es sumamente importante debido a la influencia legal que posee sobre el mercado. Sin embargo, con respecto a este punto, Honneth no hace referencia directa a la intervención del Estado para mejorar las fallas del mercado; es decir, no está pensando en una corrección que permita alcanzar un estado de equilibrio. Honneth explicita que aquello que vuelve legítima una interacción del mercado no es el permiso para perseguir intereses egocéntricos, sino el hecho de que la misma integración de intereses individuales permita que la libertad de un sujeto sea la condición de la libertad de otro ${ }^{89}$.

En otras palabras, Honneth está construyendo su teoría sobre las democracias liberales contemporáneas, y esta teoría debe, en la definición de libertad social, propiciar el reconocimiento de todos los miembros de la sociedad. Sobre todo, a partir de la inseparabilidad de las esferas, es posible explicar por qué es necesario que el mercado sea una esfera de libertad social, capaz de fundamentar, además, una nueva teoría de la justicia. Las tres esferas consideran que la realidad es cambiante y que en cada con-

87 Cohen, G. A. (2011). ¿Por qué no el socialismo? Buenos Aires. Katz, 40.

88 Cfr. Honneth. El derecho de la libertad. Ob. cit., 69.

89 Cfr. ibídem, 240. 
texto se requiere un análisis crítico de los valores y prácticas sociales. La propuesta de Honneth se origina tras la constatación histórica y sociológica de que las teorías actuales no habían asumidos los cambios sociales. Según Honneth, autores como Rawls y Habermas tampoco han visto los efectos que las teorías de la justicia, basadas en una noción individualista de la libertad, producen en la sociedad, tales como la proliferación de actitudes egoístas. Estos efectos podrían evitarse si se aceptara que los hombres también son capaces de desenvolverse en un entramado social en el cual se promueva la comunidad, la solidaridad y el reconocimiento de la dignidad humana. El mercado es necesario para la teoría institucional de la justicia porque hace falta que las prácticas sociales de este contribuyan a difundir una visión no individualista del orden social. El ser humano debe ser entendido como un ser que depende y necesita de otros para construir una sociedad justa. Únicamente reconociendo al otro como parte de la propia libertad, y comprendiendo que, paradójicamente, nuestra libertad se despliega al máximo cuando nos vinculamos con los demás, es como podemos ser justos los unos con los otros.

\section{Conclusiones}

El mercado representa en la actualidad una de las instancias donde los individuos actúan para obtener la maximización de sus propios beneficios. Se ha asumido que nuestra libertad individual consiste en desenvolverse y desarrollarse, sin tomar en cuenta que existen millones de personas que también buscan lo mismo. Por esta razón, la postura de Honneth implica replantearse el modo en que hemos comprendido nuestra libertad. Somos seres que dependemos unos de otros. En efecto, una teoría de la justicia requiere que nos preguntemos acerca de la distribución de bienes pero, sobre todo, exige que nos planteemos el modo en que nos relacionamos los unos con los otros.

La propuesta de las esferas de libertad social nos muestra que el mercado es solo una parte de la realidad social y que funciona a partir de la conciliación entre las relaciones humanas y la vida política. En otras palabras, hablar de justicia es preocuparse de que la sociedad pueda ser reconocida como una entidad compuesta por seres con dignidad que buscan ser libres. Si bien es cierto que la propuesta de Honneth es demasiado esperanzadora con respecto a las sociedades contemporáneas, su reconstrucción normativa de las esferas es un ejemplo de que poseemos una concepción errada sobre las instituciones y los seres humanos. Aunque el mercado se encuentre lejos de fomentar el reconocimiento y la libertad social, puede llegar a hacerlo si los individuos comprenden que en este se 
encuentra la clave para una sociedad más justa. Evidentemente, es una tarea sumamente complicada; sin embargo, es un planteamiento en el que vale la pena ahondar.

Además, es preciso aclarar que Axel Honneth no posee la intención de moralizar a nadie, simplemente desea aportar una nueva manera de concebir la libertad humana y, por tanto, cambiar el modo en que construimos las teorías sobre la justicia. Sobre todo, al ser consciente de que las democracias liberales contemporáneas le atribuyen un gran papel al mercado, Honneth argumenta que este es necesario para reconocer la dignidad humana de todos los individuos. Sabe que las relaciones entre los seres humanos se rigen por intercambios de transacción, por lo que es necesario destacar el importante papel que poseen las corporaciones en las sociedades y mostrar que, gracias a ellas, podemos reconocer que nos necesitamos los unos a los otros para ser justos.

\section{Referencias}

Arrese Igor, H. O. (2017). "El mercado como una esfera de la libertad social". Filosofía de la Economía 6 (2): 139-53, http://ppct.caicyt.gov.ar/index.php/filoecon/ article/view/11229.

Berlin, I. (1969). “Two Concepts of Liberty”. En On Liberty. New York. Oxford University Press.

Cohen, G. A. (2011). ¿̇Por qué no el socialismo? Buenos Aires. Katz.

Coronado, C. (2018). "La libertad como condición de la justicia según Axel Honneth". Revista de filosofía open insight, 9 (15), 147-171, https://doi.org/10.23924/ oi.v9n15a2018.pp147-171.263.

Coronado-Angulo, C. (2019). Razón instrumental, sociedad e instituciones. Una semblanza de Max Weber y la Escuela de Frankfurt. Pamplona. EUNSA.

De Boer, K. (2013). "Beyond Recognition? Critical Reflections on Honneth's Reading of Hegel's Philosophy of Right". International Journal of Philosophical Studies, 21, https://doi.org/10.1080/09672559.2012.760171.

Freyenhagen, F. (2015). "Honneth on Social Pathologies: A Critique". Critical Horizons, 16 (2), 131-152, https://doi.org/10.1179/1440991715Z.00000000044.

Haber, S. (2007). "Recognition, Justice and Social Pathologies in Axel Honneth's Recent Writings". Revista de ciencia politica (Santiago), 27 (2), 159-170, https://doi. org/10.4067/S0718-090X2007000300009.

Honneth, A. (1995). "Social Deficit of Critical Theory". En New Perspectives on Max Horkheimer. MIT Press, 187-214.

Honneth, A. (1997). La lucha por el reconocimiento. Por una gramática moral de los conflictos sociales. Barcelona. Grijalbo.

Honneth, A. (2001). Recognition or Redistribution? Changing perspectives on the Moral Order of Society, 43-55, https://doi.org/10.1177/02632760122051779. 
Honneth, A. (2004). "Recognition and Justice: Outline of a Plural Theory of Justice”. Acta Sociológica, 47 (4), 351-364. Retrieved from http://www.jstor.org.proxy. library.nd.edu/stable/4195052.

Honneth, A. (2007). Reificación: Un estudio en la teoría del reconocimiento. Buenos Aires. Katz.

Honneth, A. (2009). Crítica del poder: Fases en la reflexión de una Teoría Crítica de la sociedad (Teoría y crítica $n^{\circ} 23$ ) (Spanish Edition). Antonio Machado Libros. Edición de Kindle.

Honneth, A. (2012). The I in We. Cambridge. Polity Press.

Honneth, A. (2014). El derecho de la libertad. Buenos Aires. Katz.

Honneth, A., \& Farrell, J. (1997). "Recognition and Moral Obligation". Social Research, 64 (1), 16-35. Retrieved December 4, 2020, from http://www.jstor.org/stable/40971157.

Honneth, A. \& Fraser, N. (2006). ¿Redistribución o reconocimiento? Madrid. Morata.

Honneth, A. \& Markle, G. (2004). "From Struggles for Recognition to a Plural Concept of Justice: An Interview with Axel Honneth”. Acta Sociológica, 47 (4), 383391, http://www.jstor.org.proxy.library.nd.edu?url=https://www.jstor.org/stable/4195052.

Islam, G. (2012). "Recognition, Reification, and Practices of Forgetting: Ethical Implications of Human Resource Management". Journal of Business Ethics, 111 (1), 37-48, https://doi.org/10.1007/s10551-012-1433-0.

Jay, M. (1989). La imaginación dialéctica: Historia de la Escuela de Frankfurt y el Instituto de Investigación Social 1923-1950. Madrid. Taurus.

Jeffries, S. (2017). Grand Hotel Abyss: The Lives of the Frankfurt School. Scotland. Verso.

Jütten, T. (2015). "Is the Market a Sphere of Social Freedom?" Critical Horizons, 16 (2), 187-203, https://doi.org/10.1179/1440991715Z.00000000047.

Klikauer, T. (2015). Hegel's Moral Corporation. Palgrave Macmillan UK, http://ebookcentral.proquest.com/lib/ndlib-ebooks/detail.action?docID=4082301.

Lysaker, O. (2017). “Institutional Agonism: Axel Honneth's Radical Democracy”. Critical Horizons, 18 (1), 33-51, https://doi.org/10.1080/14409917.2017.1275168.

McNay, L. (2008). "The Trouble with Recognition: Subjectivity, Suffering, and Agency". Sociological Theory, 26 (3), 271-296, https://doi.org/10.1111/j.14679558.2008.00329.x.

McNay, L. (2015). "Social Freedom and Progress in the Family: Reflections on Care, Gender and Inequality”. Critical Horizons, 16 (2), 170-186, https://doi.org/10.117 9/1440991715Z.00000000046.

North, D. (1995). Las instituciones, el cambio institucional, el desempeño económico. México. FCE.

Okochi, T. (2012). "Freedom and Institution: Theory of Justice as Hegelian 'Sittlichkeitslehre' in a Honneth's 'Das Recht der freiheit'". Hitotsubashi Journal of Social Studies, 44 (1), 9-19, www.jstor.org/stable/43294600.

Petersen, A. y Willig, R. (2002). "An interview with Axel Honneth: The Role of Sociology in the Theory of Recognition". European Journal of Social Theory, 5 (2), 265-277, https://doi-org.proxy.library.nd.edu/10.1177/13684310222225441. 


\section{CECILIA GALLARDO-MACIP}

Roberts, N. (2009). Recognition, Power, and Agency: The Recent Contributions of Axel Honneth to Critical Theory. 37 (2), 296-309, https://doi. org/10.1177/0090591708329653.

Schmitz, V. (Ed.). (2019). Axel Honneth and the Critical Theory of Recognition. Palgrave Macmillan, https://doi.org/10.1007/978-3-319-91980-5.

Van Leeuwen, B. (2007). "A Formal Recognition of Social Attachments: Expanding Axel Honneth's Theory of Recognition”. Inquiry, 50 (2), 180-205, https://doi. org/10.1080/00201740701239897.

Wiggershaus, R. (2011). La Escuela de Fráncfort. México. FCE.

Zúñiga, L. A. \& López, H. V. (s. f.). "La teoría del reconocimiento de Axel Honneth como teoría crítica de la sociedad capitalista contemporánea". Reflexión Política, 20 (39), 263-280, https://www.redalyc.org/jatsRepo/110/11058501016/html/index. html.

Zurn, C. F. (2005). "Recognition, Redistribution, and Democracy: Dilemmas of Honneth's Critical Social Theory". European Journal of Philosophy, 13 (1), 89126, https://doi.org/10.1111/j.0966-8373.2005.00223.x. 